\title{
COMPARING THE TIME-CONSUMPTION OF DESTRUCTIVE AND NON-DESTRUCTIVE ForMS OF MEASUREMENT IN THE AUTOMOTIVE INDUSTRY
}

\author{
Nikola Skřivanová, Martin Melichar
}
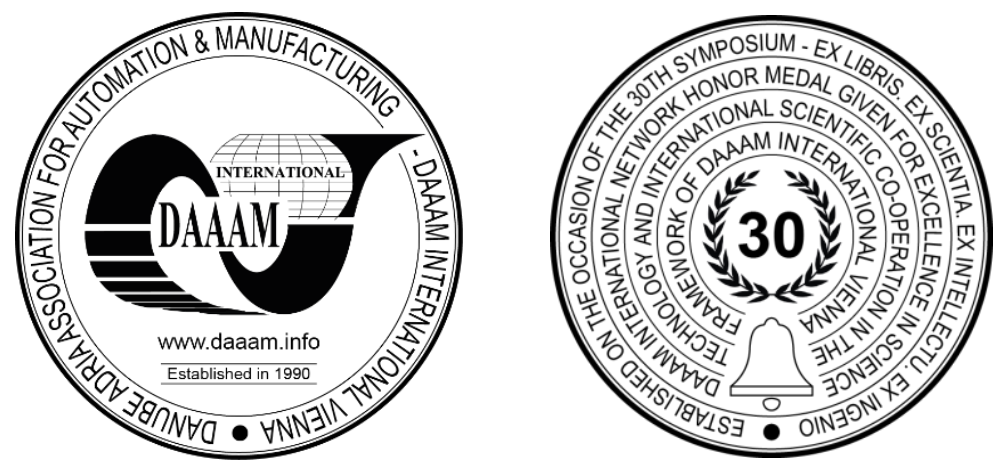

This Publication has to be referred as: Skrivanova, N[ikola] \& Melichar, M[artin] (2019). Comparing the TimeConsumption of Destructive and Non-Destructive Forms of Measurement in the Automotive Industry, Proceedings of the 30th DAAAM International Symposium, pp.1003-1007, B. Katalinic (Ed.), Published by DAAAM International, ISBN 978-3-902734-22-8, ISSN 1726-9679, Vienna, Austria

DOI: $10.2507 / 30$ th.daaam.proceedings.139

\section{Abstract}

The article presents a comparison of the time-consumption of destructive and non-destructive forms of measurement in the automotive industry. X-ray, CT control system Y. Cougar SMT which allow non-destructive measurement, and CMM - Vertex 311 UM, in which the measured dimensions are not always accessible and therefore cannot be measured without destructive intervention.

The aim of the experiment was to compare, on a representative piece, the approximate time consumption of measurements on individual measuring machines. The results of this experiment were a useful basis for selecting an effective form of measurement in terms of time consumption on the above machines.

Keywords: CMM; X-ray; CT; measurement; experiment;

\section{Introduction}

The automotive industry is one of the most competitive industries in engineering. Companies are continually struggling to prove their reputation. For this reason, progressive technology, product features and customer service are constantly evolving. Whereas the information and telecommunication industries deal with lifecycles from 0.5 to 3 years on average, the automotive industry designs their products with lifetimes of 6 to 10 years. Accurate measurement is an essential prerequisite for improving the quality of production in the automotive industry and it is one of the basic ways of obtaining quantitative information about the monitored quantity. It has become a fundamental prerequisite for trust in the exchange of goods and it is also one of the important conditions for efficient production. [1], [2]

The research was based on the requirement of a testing laboratory of a company that produces components for the automotive industry. The current situation in the laboratory corresponds to the fact that the laboratory technicians do not have fixed rules for the selection of the machine. The technician chooses the measuring machine for inspection at his own discretion. An improperly selected machine creates a problem of overloading machines or, on the contrary, their capacity 
is not used. Another problem associated with poor machine choice is unnecessarily time-consuming measurements that could be made with the right choice more efficiently. The requirement of the testing laboratory was to assess the approximate time consuming of the measurements on CMM (destructive form of measurement) and X-ray, CT control system (Non-destructive form of measurement). Therefore, the experiment described below was designed. The results of this experiment will help the engineer to streamline machine selection based on time consuming measurements and time savings. The experiment is a part of the research. The results of the experiments will be used to elaborate a comprehensive methodology of the testing laboratory, which is a part of further research. The company is certified according to IATF 16 949.

Attributed to Galileo Galilei, the famous quote, "Count what is countable, measure what is measurable. What is not measurable, make measurable" is fundamental to modern management. It follows from this statement that even the great Renaissance pioneer was aware of the importance of measuring. The IATF 16949 standard for the automotive industry makes it clear that if a customer requests any measurements of some of the final products from the manufacturer, the manufacturer is obliged to make the measurements. If the conditions are not adequate, the manufacturer is obliged to provide a suitable alternative. Demands for product accuracy are constantly increasing, especially in the automotive industry. It thus becomes the basis not only of ensuring the production of precise dimensions, but also of their control by ensuring a reliable and competent measurement process. In practice, however, not only this fact but also time plays a role. The customer has clear requirements for product quality. Within the framework of IATF 16949 , it can obtain, and in most cases requires, proof of the dimensional accuracy of the required product. [3], [4]

The article presents a comparison of the time-consumption of destructive and non-destructive forms of measurement in the automotive industry. The evaluated measuring machines are: CMM - Vertex $311 \mathrm{UM}$ and X-ray, CT control system - Y. Cougar SMT, which allows measurement by X-ray or CT model. These measuring machines have their variables, for example: measurement speed, resolution, accuracy, repeatability, reproducibility, destructive / non-destructive form of analysis, etc. There are many factors. The time factor is evaluated in the experiment for the reasons listed above.

In today's industrial production, CMMs are one of the cornerstones of control. They allow simple dimension measurements based on drawings, not to mention other complicated characteristics such as shape evaluation or position deviations from a 3D model. Pitfalls occur when the measured dimensions are inaccessible. In such cases, destruction of the measured object is necessary. X-ray and CT measurement systems are increasingly being used in the automotive industry for non-destructive measurement. This technology has undergone considerable development over the years. It is successfully used not only in medicine, but also in non-destructive visual inspections and accurate measurements in the industrial sphere. X-ray and CT measurement systems allow us to look at the internal and external geometry of the measured part. Furthermore, they allow measurements of characteristics otherwise unreachable by contact measurement methods. All measurements for comparing the time consumption of destructive and non-destructive measurements based on the experiment were carried out with the participation of an employee of the accredited metrology laboratory of the Regional Institute of Technology, Faculty of Mechanical Engineering, University of West Bohemia. [6], [7], [8] , [9], [10]

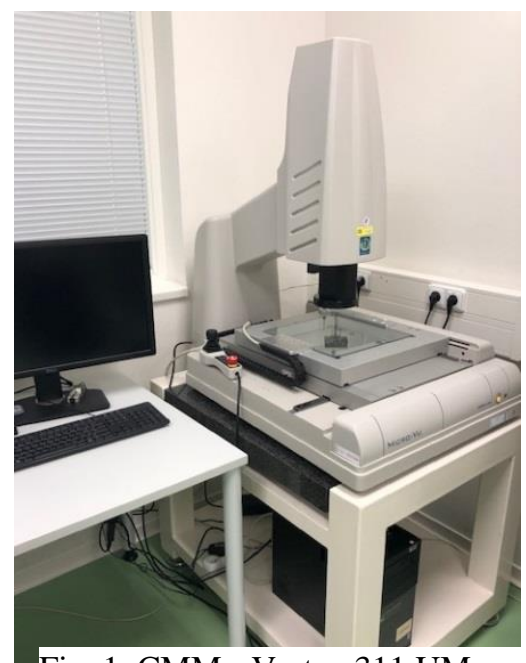

Fig. 1. CMM - Vertex 311 UM

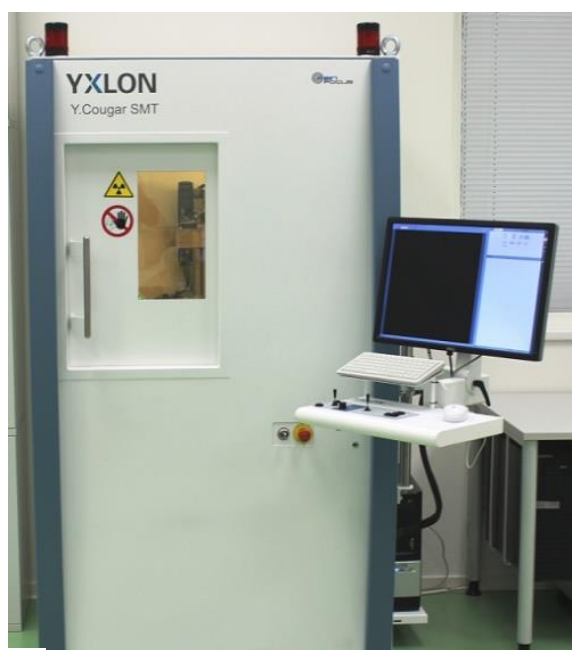

Fig. 2. X-ray, CT control system - Y. Cougar SMT 


\section{Experiment description}

The length, height and width of a $10 \mathrm{~mm}$ ceramic end gauge (see Fig. 3.) were measured experimentally on different measuring machines. Time demands were verified by measuring 1, 5, 10 and 15 pieces. Each measuring machine works on a different principle. The preparation of the machines, clamping of the samples for measurement and measurement itself took different lengths of time.

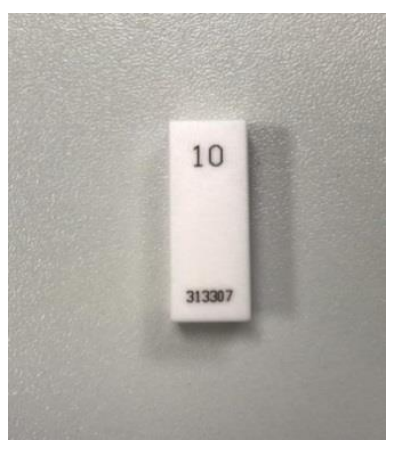

Fig. 3. 10mm ceramic gauge block

The aim of the experiment is to determine the time consumption of measurements on a selected gauge. It is also intended to indicate the suitability of measuring machines for individual and series measurements. Initial measurement conditions are given in Table 1.

\begin{tabular}{|c|c|c|c|}
\hline Initial measurement conditions: & CMM & RTG & CT \\
\hline Temperature $\left[{ }^{\circ} \mathrm{C}\right]$ & $20 \pm 1$ & $20 \pm 1$ & $20 \pm 1$ \\
\hline Humidity $[\%]$ & $45 \pm 1$ & $45 \pm 1$ & $45 \pm 1$ \\
\hline
\end{tabular}

Table 1. Initial measurement conditions of measurement using CMM, RTG a CT

Measurement on CMM was performed by optical method. To measure the length, height and width of the gauge block, it was necessary to create two programs for two different views. The time required increases with the creation of programs and double clamping of the gauge for each program. The CMM is capable of operating independently under the operator's control based on a pre-created program. Therefore, it is a good choice with an increasing number of measured pieces. The disadvantage is when the measured dimension is not fully accessible. In the case of customer complaints, the customer's consent to the disassembly of the product is not always given. If customer consent is given or internal analysis is involved, the risk of product disassembly should be considered. The resulting times are shown in Table 2.

\begin{tabular}{|c|c|c|c|c|}
\hline Sequence of individual steps & $1 \mathrm{pc}$ & $5 \mathrm{pc}$ & $10 \mathrm{pc}$ & $15 \mathrm{pc}$ \\
\hline $\begin{array}{c}\text { Creating a program for length and width of ceramic } \\
\text { gauge [min] }\end{array}$ & 4.5 & 4.5 & 4.5 & 4.5 \\
\hline Create a program for height of ceramic gauge [min] & 3.0 & 3.0 & 3.0 & 3.0 \\
\hline Clamping of ceramic gauge (2x) [min] & 1.0 & 5.0 & 10.0 & 15.0 \\
\hline Measuring length and width of ceramic gauge[min] & 1.5 & 7.5 & 15.0 & 22.5 \\
\hline Measuring height of ceramic gauge [min] & 1.0 & 5.0 & 10.0 & 15.0 \\
\hline Total [min] & 11.0 & 25.0 & 42.5 & 60.0 \\
\hline
\end{tabular}

Table 2. Results for CMM 
$\mathrm{X}$-ray measurement is relatively fast, even in the case of double clamping. Most of the time was taken up setting all the parameters and preparing for the measurement. Due to X-ray (2D) imaging capabilities, measurement was performed twice from two different views. First, the length and height were measured and then the width was measured after the gauge was rotated. X-ray measurement provides a certain advantage in case of poor accessibility of the measured dimension. This device is able to measure external and internal dimensions using X-ray radiation without the need for destructive intervention in a relatively short time. The density of the material to be measured is a significant limitation, as X-rays have limited ability to pass through certain materials. The advantage is that data can be stored for analysis over a longer period of time without the need to store samples. The resulting times are shown in Table 3.

\begin{tabular}{|c|c|c|c|c|}
\hline Sequence of individual steps & $1 \mathrm{pc}$ & $5 \mathrm{pc}$ & $10 \mathrm{pc}$ & $15 \mathrm{pc}$ \\
\hline Preparation before measurement [min] & 6.0 & 6.0 & 6.0 & 6.0 \\
\hline Clamping of ceramic gauge (2x) [min] & 1.0 & 10.0 & 15.0 & 20.0 \\
\hline Measuring length and width of ceramic gauge[min] & 1.0 & 10.0 & 15.0 & 20.0 \\
\hline Measuring height of ceramic gauge [min] & 0.5 & 2.5 & 5.0 & 7.5 \\
\hline Total [min] & 7.5 & 28.5 & 41 & 53.5 \\
\hline
\end{tabular}

Table 3. Results for RTG

Measuring on CT despite its ability to measure all 3 dimensions in a 3D model is the most time consuming. This measurement is least effective in terms of time. The actual scan and conversion of individual X-ray images to a 3D model is very time consuming. Therefore, this method seems unsuitable for serial measurements. However, the 3D model is able to provide all relevant information about the measured piece. The advantage is a multiposition $2 \mathrm{D}$ cross section. This gives access to the internal structure, and therefore enables measurement of poorly accessible dimensions or detection of imperfections within the internal structure (pores, cracks, etc.). Here, too, it is possible to store data for analysis even for a longer period of time. The resulting times are shown in Table 4.

\begin{tabular}{|c|c|c|c|c|}
\hline Sequence of individual steps & $\mathbf{1} \mathbf{~ p c}$ & $\mathbf{5} \mathbf{~ p c}$ & $\mathbf{1 0} \mathbf{~ p c}$ & $\mathbf{1 5} \mathbf{~ p c}$ \\
\hline Preparation before measurement [min] & 6.0 & 6.0 & 6.0 & 6.0 \\
\hline Clamping of ceramic gauge (2x) [min] & 1.5 & 7.5 & 15.0 & 22.5 \\
\hline Scan of CT [min] & 7.0 & 35.0 & 70.0 & 105 \\
\hline Measurement of length, width and height [min] & 3.0 & 15.0 & 30.0 & 45.0 \\
\hline Altogether [min] & 17.5 & 63.5 & 121 & 178.5 \\
\hline
\end{tabular}

Table 4. Results for CT

\section{Conclusion}

The research was based on the requirement of a testing laboratory of a company that manufactures components for the automotive industry. The technician chooses the measuring machine for inspection at his own discretion. This fact leads to problems associated with overloading the capacity of measuring machines and inappropriately chosen machine in terms of time consumption. The requirement of the testing laboratory was to assess the approximate time consuming of the measurements on CMM (destructive form of measurement) and X-ray, CT control system (Non-destructive form of measurement). The proposed experiment will bring more effective choice of measuring machine, even distribution of work (measuring) on individual machines, saving time. The results of the experiment will be used to develop a comprehensive methodology for the testing laboratory, which is part of further research. 
The testing laboratory of the company supplying parts for the automotive industry has requested the verification of approximate time consuming measurements on CMM (destructive form of measurement) and X-ray, CT control system (non-destructive form of measurement). The desired result was to make the measuring machine more effective on the basis of time consuming measurements, saving time, symmetrical distribution of measuring machines utilization.

The results of this experiment will be used as a basis for the development of a comprehensive measurement methodology for operators, which will be part of further research. The article deals with the comparison of destructive and nondestructive forms of measuring dimensions in the automotive industry in terms of time consumption. The results of this experiment serve as a useful basis for selecting an effective form of measurement in terms of time consumption on the above-mentioned machines. Tables 2., 3., 4. are the output of a time-consumption experiment, where the approximate time-consumption of measuring on different machines was verified on a representative piece. The representative piece was a ceramic gauge block. This representative piece was chosen for a minimum of two clamping measurements, which represents $80 \%$ of the products solved by testing laboratories in the automotive industry.

Of course, the choice of the measuring machine depends on the required number and accessibility of the measured dimensions, the number of measured pieces and the number of clamps. For this reason, measurements were carried out first on 1, 5, 10 and 15 pieces. X-ray measurements proved to be the most effective, despite the need for double clamping. Measurement with this method also provides additional benefits in the form of measurements of internal dimensions without the need for destructive intervention and storage of data for later additional analyses. A disadvantage and limitation is the density of the measured material. Next in line is CMM measurement. Measuring on CMM becomes a more advantageous choice with an increasing number of measured pieces. The disadvantage here is the measurement of inaccessible dimensions and internal dimensions. In the case of customer complaints, the customer's consent to the disassembly of the product is not always given. If customer consent is given or internal analysis is involved, the risk of product disassembly should be considered. The least effective in terms of time is measurement using a CT model. The scan itself is very time consuming. The advantage is that the CT model allows all measurements together and provides all relevant information about the part. Despite these advantages, measurements on this machine are not suitable for series measurement.

\section{Acknowledgments}

This paper was supported by the project : SGS-2019-008 "Research and Development for Innovation in the Field of Manufacturing Technology - Machining Technology III.

\section{References}

[1] Bicova K. Kutlwaser J., Sklenicka J.: (2016). Issue of High Precision Manufacturing Analysis in Automotive Industry, Proceedings of the 27th DAAAM International Symposium, ISBN 978-3-902734-08-2, ISSN 1726-9679, Vienna, Austria DOI: 10.2507/27th.daaam.proceedings.052

[2] Sivria S., Hennersdorfb S., Krallmannc H.: (2016). Enhanced Method for Quality-fit (ISO 9001) Operations within the Automotive Industry, Proceedings of the 26th DAAAM International Symposium, ISBN 978- 3-902734-07-5, ISSN 1726-9679, Vienna, Austria DOI: 10.2507/26th.daaam.proceedings.083

[3] VolkanTürker M.: A model proposal oriented to measure technological innovation capabilities of business firms a research on automotive industry, Procedia - Social and Behavioral Sciences 41 ( 2012 ) 147 - 159 , doi: 10.1016/j.sbspro.2012.04.019

[4] Melichar M., Kubátová D., Kutlwaše J.: (2018). The Influence of humidity on ABS plastic measurement results, Proceedings of the 29th DAAAM International Symposium, ISBN 978-3-902734-20-4,ISSN 1726-9679, Vienna, Austria DOI: 10.2507/29th.daaam.proceedings.065

[5] Keran, Z., Mihaljevic M., Horvatic Novak A., Runje B.: (2018). Non Destructive Testing of Forge Welding Joint Errors, Proceedings of the 29th DAAAM International Symposium, ISBN 978-3-902734- 20-4, ISSN 1726-9679, Vienna, Austria DOI: 10.2507/29th.daaam.proceedings.024

[6] Horvatic A., Runje B., Butkovic D.: (2016). Influence of Geometrical Magnification on Computed Tomography Dimensional Measurements, Proceedings of the 27th DAAAM International Symposium, ISBN 978-3-902734- 082, ISSN 1726-9679, Vienna, Austria DOI: 10.2507/27th.daaam.proceedings.090

[7] Melichar M., Kubatova D., Kutlwaser J., (2016). CMM Measuring Cycle and Human Factor, Proceedings of the 27th DAAAM International Symposium, ISBN 978-3-902734-08-2, ISSN 1726-9679, Vienna, Austria DOI: 10.2507/27th.daaam.proceedings.055

[8] D. Kubátová, M. Melichar, J. Kutlwašer, Evaluation of Repeatability and reproducibility of CMM equipment, In Procedia Manufacturing, Volume 13, 2017, Pages 558-564, ISSN 2351-9789, https://doi.org/10.1016/j.promfg.2017.09.091.

[9] A.Goulas K., Dery S., Dietrich P., R.Johnson G., Grippo A., ChungWang Y., Gross E.: X-ray tomography measurements identify structure-reactivity correlations in catalysts for oxygenates coupling reactions, Catalysis Today, Volume 336, 1 October 2019, Pages 186-192, https://doi.org/10.1016/j.cattod.2018.12.012

[10] Płowucha W.. Jakubiec W.. Wojtyła M.: Possibilities of CMM Software to Support Proper Geometrical Product Verification. Procedia CIRP. Volume 43. 2016. Pages 303-308. ISSN 2212-8271. http://dx.doi.org/10.1016/j.procir.2016.02.124 